\title{
Improvement of the Dynamic Response of Robust Sliding Mode MPPT Controller-Based PSO Algorithm for PV Systems under Fast-Changing Atmospheric Conditions
}

\author{
Dieudonné Marcel Djanssou $\mathbb{D}^{\mathrm{D}},{ }^{1}$ Abdouramani Dadjé $\mathbb{D}^{\mathrm{D}},{ }^{1,2}$ Ahmat Tom $\mathbb{D}^{3}$ \\ and Noël Djongyang $\mathbb{1}^{1}$ \\ ${ }^{1}$ Department of Renewable Energy, National Advanced School of Engineering of Maroua, University of Maroua, Cameroon \\ ${ }^{2}$ School of Geology and Mining Engineering, University of Ngaoundéré, Cameroon \\ ${ }^{3}$ Department of Energy Engineering, University Institute of Technology, University of Ngaoundéré, Cameroon \\ Correspondence should be addressed to Noël Djongyang; noeldjongyang@gmail.com
}

Received 27 November 2020; Revised 7 April 2021; Accepted 18 May 2021; Published 1 June 2021

Academic Editor: Pierluigi Guerriero

Copyright (C) 2021 Dieudonné Marcel Djanssou et al. This is an open access article distributed under the Creative Commons Attribution License, which permits unrestricted use, distribution, and reproduction in any medium, provided the original work is properly cited.

\begin{abstract}
To get the maximum power point (MPP), the algorithms developed in the literature fail for the most part when the atmospheric conditions vary rapidly. This paper presents the optimization by the swarm particles (PSO) of a sliding mode controller (SMC) to optimize photovoltaic systems (PV) evolving under the conditions of a rapid variation of the sunshine. The stochastic PSO algorithm is used in particular to determine the optimal gains of the sliding mode controller, and this algorithm guarantees the stability and global fast convergence of the system. Efficiency of the proposed hybrid algorithm is proved by using a Solarex MSX-60 module connected to a step-up DC-DC converter supplying a resistive load. The performances are compared to the conventional perturb and observe technique (P\&O), PSO, CUCKOO, grey wolf optimization (GWO), and Whale Optimization Algorithm (WOA) in terms of convergence speed, i.e., $0.05 \mathrm{~s}$, tracking speed after extreme change in irradiance $0.03 \mathrm{~s}$, high Ability to track large changes in power before $1 \mathrm{~s}$. Simulation results show that this technique is effective in conditions of a rapid variation of the irradiance.
\end{abstract}

\section{Introduction}

Growing concerns about environmental issues and the energy crisis have attracted many interests towards renewable energy sources. Among these sources, the photovoltaic (PV) application received special attention due to the distinctive advantages such as ease of allocation, reliability, low maintenance, zero fuel, and noise. In addition to these factors, there are the falling costs and prices of solar modules, the efficiency of solar cells, and improved manufacturing technology. However, these advantages have long been inhibited by the complexity of its operation. This is because PV modules have nonlinear characteristics which are determined by solar irradiance and temperature which affects the overall output power of the system $[1,2]$.
In fact, the irradiance and the temperature of the cell are the factors, which strongly influence the output I-V characteristic of the photovoltaic generator [3]. On the other hand, the constant concern of industrial environments, research laboratories, and homes is to have the maximum available power in a short time and whatever the atmospheric conditions. To account for this nonlinearity, researchers to increase the efficiency of the system implemented maximum power point tracking (MPPT) techniques. This in-depth research aimed at increasing the energy efficiency of PVS systems has led to the development of MPPTs (Perturb and Observe $[4,5]$, conductance increment [6-8], fractional short circuit current [9], fractional open-circuit voltage [10], synergistic nonlinear fractional control [11], and model predictive control [12]) proposed over the past two decades. The best 
known MPPTs methods are Perturb and Observe and Increment Conductance [13]; they have several advantages such as simplicity of structure, low cost, smooth implementation, and fewer parameter measurements. However, these methods fail to locate the point of maximum power under rapidly changing environmental conditions [14]. The limitation of conventional algorithms is overcome by modern MPPT methods such as Modified incremental conductance [15], gray wolf optimization [16], WO algorithm [14], Jaya algorithm [17] [18], modified sine-cosine optimized [19], genetic algorithm [20,21], artificial bee colony [22], Modified Butterfly Optimization Algorithm [23], Ant Colony Optimized [24], neural networks (ANN) $[25,26]$ particle swarm optimization (PSO) [27, 28], and fuzzy logic (FLC) [29-32]. These methods are chosen according to the performance parameters (complexity, speed of convergence, cost, number of sensors, and reliability). A classification based on these parameters is presented in [3]. These techniques are for the most part stable and precise under stable conditions but less precise in the event of instability or rapid variations in climatic conditions or variations in load. Algorithms based on fuzzy logic and neural networks have demonstrated rapid convergence and high performance under various environmental condition, but the implementation of these algorithms can be overly complex. In terms of tracking speed, these metaheuristic algorithms are slower than their conventional counterparts $[13,14,33]$. A general problem associated with MPPT algorithms is the transient oscillation of the output voltage of the system. This is why the cheap MPPT control algorithm would be less complex, inexpensive, and able to quickly converge to the MPP with negligible oscillation [34]. Based on issues such as lower tracking accuracy, high convergence time, high computational load, and low tracking efficiency in conventional and modern MPPT techniques, sliding mode control (SMC) has received a lot of attention. Attention due to its advantages such as guaranteed stability, robustness against parametric variations, rapid dynamic response, and ease of implementation $[35,36]$. This is why sliding mode has been approved in control fields such as robotics and motor control to overcome certain parametric variations as well as unknown internal and external disturbances [37-40]. The sliding mode was developed by Utkin in 1977 for systems with variable structures [41] and is based on the theory of nonlinear control, making it the ideal candidate for attenuating the nonlinearity of PV systems. Several approaches are accredited to implement sliding mode in PVS systems mainly two types of strategies namely single loop and cascade loop. MPP lookup is not required for a single loop. The switching surface is designed to converge towards zero as the system approaches the MPP [42-45]. Moreover, in the case of cascade loop control, the outer loop is dedicated to search and the inner loop is dedicated to following the MPP with conventional and intelligent algorithms (P\&O [46, 47], linear estimation [48], and fuzzy logic [49]). The tracking loop must be faster than the search loop to precisely reach the MPP. Garraoui et al. [50] studied two MPPT algorithms. Fuzzy logic and sliding mode MPPT controllers are compared under varying weather conditions as well as in the case of varying loads. The simulation results obtained

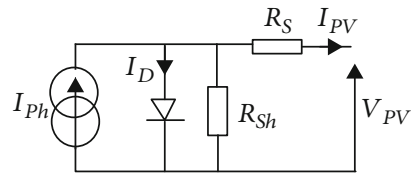

Figure 1: PV cell equivalent circuit.

TABle 1: Specifications of PV panel.

\begin{tabular}{lcc}
\hline Parameter & Name & Value \\
\hline Pmax & Maximun power & $60 \mathrm{~W}$ \\
Vmpp & Optimun operating voltage & $17 \mathrm{~V}$ \\
Impp & Optimun operating current & $3.5 \mathrm{~A}$ \\
Voc & Open circuit voltage & $21.1 \mathrm{~V}$ \\
Isc & Short-circuit current & $3.8 \mathrm{~A}$ \\
\hline
\end{tabular}

showed that the sliding mode MPPT controller performs well under these conditions, because it accurately follows the new MPP with high output power compared to fuzzy logic. Many authors [42, 45, 51-57] have proposed various MPPT methods based on the sliding mode. However, the performance of the control in sliding mode is difficult to obtain, because the choice of the control gain is directly associated with the upper limit of uncertainties difficult to model. In general, the guarantee of the robustness of the system remains possible by the choice of a high control gain, then inducing the phenomenon of chatter, which occurs in the sliding modes. This phenomenon is the major drawback of the practical implementation of control in sliding mode, because it could excite the unmodeled dynamics leading to the instability of the system [58]. To cope with this situation, different strategies have been presented in the literature, including second-order sliding mode control as well as hybrid methods combining sliding mode with an artificial neural network and fuzzy logic [59-63]. The approach developed under the name of Robust Control (Fast Terminal Sliding Mode Control) can converge the state of the system towards zero in a finite time; it has no discontinuous sign function and makes it possible to completely avoid the phenomenon of chattering. The sliding surface proposed by Park et al. [64] is nonlinear, designed so that the system converges in a finite time. Chiu et al. [65] have defined a sliding surface to get around the problem of singularity. The simulation results proved the rapid convergence compared to the PI controller. Asma et al. [66] developed a Fast Terminal sliding mode control where fast-tracking speed was observed in simulation results with almost no chatter fluctuation. Amirineni et al. [67] have developed integral terminal sliding mode. The system corrects the voltage drop caused by external uncertainties and input variations, which implies the rapid response of the said system. Mojallizadeh et al. [68] developed a terminal sliding mode control (TSMC) MPPT that is more efficient than conventional TSMC. Their model decreases the amplitude of the chatter by using a secondorder filter in the control law. Garcia et al. [69] have developed a sliding mode MPPT control based on terminal voltage. Small oscillation and quick dynamic response are 

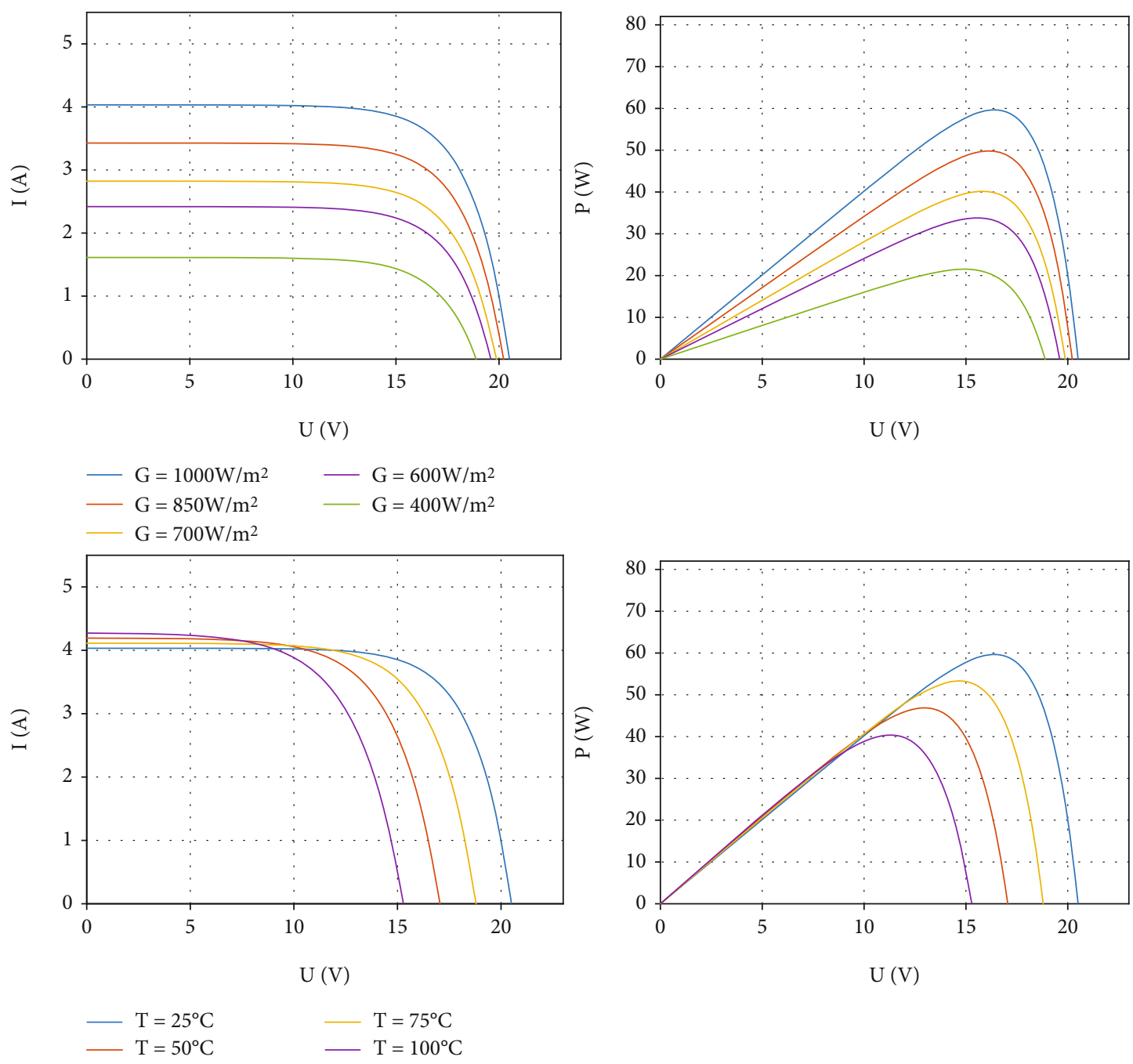

Figure 2: Characteristic I-V and V-P.

achieved by applying Terminal sliding mode control (TSMC) for MPPT. Shahdadi et al. [70] have improved the fast terminal sliding mode MPPT control. An adjustment of the coefficients is necessary. The proposed algorithm is effective in the event of partial shading. Harrag et al. [57] have developed a hybrid PSO-P\&O algorithm. The $\mathrm{P} \& \mathrm{O}$ here is variable pitch, and the PSO is used to find the optimal gains for the SMC controller to make the variable pitch $\mathrm{P} \& \mathrm{O}$ algorithm follow the MPP. Other so-called hybrid methods have demonstrated their superiority over classical and even modern algorithms (Kamalapathi et al. [71], M.Vardia et al. [72, 73], T. Choudhary et al. [74]).

In this paper, we propose the optimization of the sliding mode MPPT controller developed by Belkaid et al. [75] using the particle swarm algorithm. Unlike most control approaches using the trial and error approach to determine the sliding mode parameters (which are not the optimal parameters), the hybrid optimization method (SMC-PSO) is proposed to find the optimal design parameters to thus guarantee the rapid convergence and the overall stability of the system. The basic principle is to make good use of the operating capacity of the PSO algorithm and the robustness of the sliding mode to produce a hybrid algorithm having both capacities.

\section{PV Panel Model and Dc-Dc Converter}

2.1. PV Panel Model. To model the PV panel, the scientific community offers several models. The single diode model is the most classic described in the literature $[42,75]$. The equivalent circuit (Figure 1) consists of a current source to model the incident light flux, a diode for cell polarization phenomena, a parallel resistance due to leakage current, and a series resistance representing various contacts [76]. The general mathematical equation of PV cells is given by the following equation [77]:

Model of the photovoltaic cell:

$$
I_{\mathrm{pv}}=N_{p} I_{\mathrm{pv}}-N_{p} I_{d}\left[e^{\left(\frac{q V_{\mathrm{pv}}}{N_{s} \mathrm{AKT}}\right)}-1\right] .
$$


The inverse saturation current Io is

$$
I_{0}=I_{0 r}\left(\frac{T}{T_{r}}\right)^{3} e^{\left(\frac{E_{g} q}{K A}\left(\frac{1}{T_{r}}-\frac{1}{T}\right)\right)}
$$

The inverse saturation current at $\operatorname{Tr}$ is

$$
\begin{gathered}
I_{0 r}=\frac{I_{\mathrm{scr}}}{e^{\left(q V_{\mathrm{oc}} / N_{s} \mathrm{AKT}\right)}-1}, \\
I_{\mathrm{ph}}=\left[I_{\mathrm{scr}}+\left(K_{i}\left(T-T_{r}\right)\right)\right] \frac{E}{1000} .
\end{gathered}
$$
follows:

$$
P_{\mathrm{pv}}=I_{\mathrm{pv}} V_{\mathrm{pv}}=N_{p} I_{\mathrm{ph}} V_{\mathrm{pv}}-N_{p} I_{o} V_{\mathrm{pv}}\left[e^{\left(\frac{q V_{\mathrm{pv}}}{N_{s} \mathrm{AKT}}\right)}-1\right] .
$$

The specification of PV panel used for the simulations is presented in Table 1. Figure 2 shows the current-voltage and power-voltage curves typical of the photovoltaic module. It is clear that the PV module inherits the nonlinear characteristics of its MPP. This MPP varies with temperature and irradiance. Consequently, the power of the photovoltaic panels increases with increasing irradiance or decreasing temperature. Therefore, in order to ensure that the photovoltaic system operates at its MPP, a control algorithm is required.

2.2. DC-DC Converter. In order to extract the maximum power from the PV panel, the DC-DC converter in Figure 3 allows adaptation between the PV panel and the load.

The mathematical model of the boost converter is deduced $[13,17]$ :

$$
\left\{\begin{array}{l}
\frac{d i_{L}}{d t}=\frac{V_{\mathrm{pv}}-V_{0}}{L}+\frac{V_{0}}{L} u \\
\frac{d V_{o}}{d t}=-\frac{V_{o}}{\mathrm{RC}_{2}}+\frac{i_{L}}{C_{2}}-\frac{i_{L}}{C_{2}} u
\end{array} .\right.
$$

If we set $x=\left[\begin{array}{ll}x_{1} & x_{2}\end{array}\right]^{T_{r}}=\left[\begin{array}{ll}i_{L} & V_{0}\end{array}\right]^{T_{r}}$ then the expression, (5) can be written:

$$
\left\{\begin{array}{l}
\frac{\mathrm{dx}_{1}}{d t}=\frac{V_{\mathrm{pv}}-x_{2}}{L}+\frac{x_{2}}{L} \cdot u \\
\frac{\mathrm{dx}_{2}}{\mathrm{dt}}=-\frac{x_{2}}{\mathrm{RC}_{2}}+\frac{x_{1}}{C_{2}}-\frac{x_{1}}{C_{2}} \cdot u
\end{array} .\right.
$$

The converter is therefore described by the following nonlinear system:

$$
\dot{x}=\frac{\mathrm{dx}}{\mathrm{dt}}=f(x, t)+g(x, t) \cdot u+h .
$$

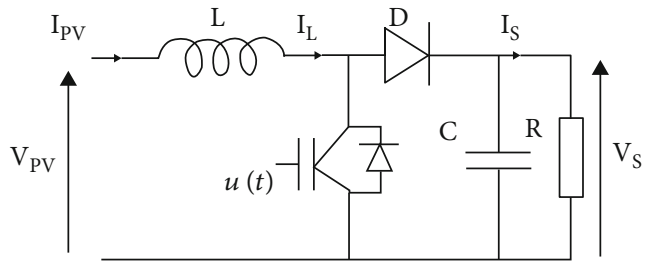

Figure 3: Boost converter.

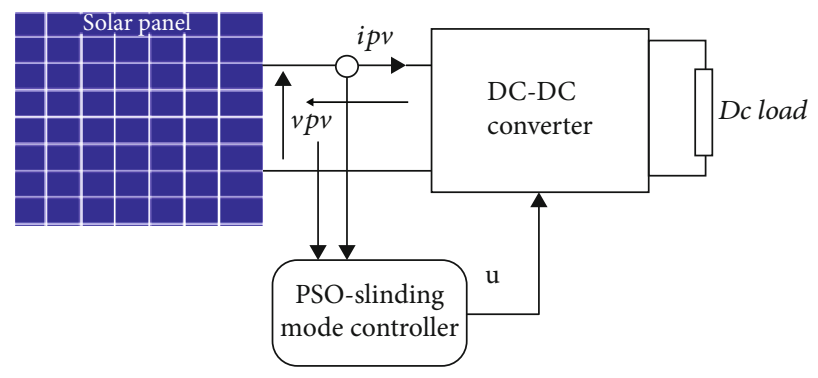

FIGURE 4: Sliding mode control.

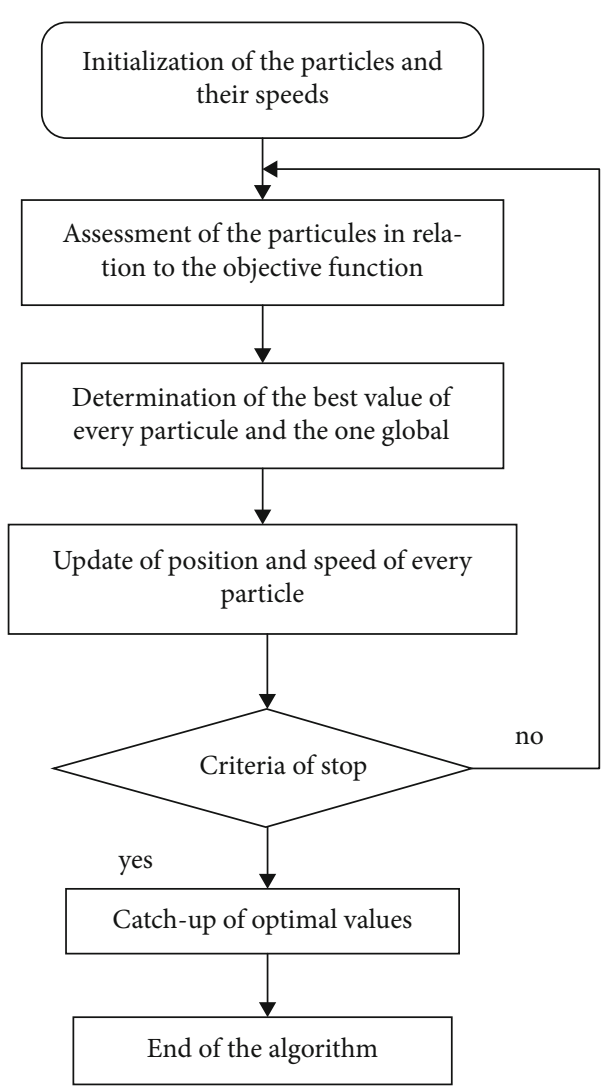

FIGURE 5: Flowchart of the PSO algorithm.

\section{Synthesis of Robust Control by Sliding Mode}

Consider the nonlinear system described by

$$
x^{(n)}=f(x, t)+g(x, t) \cdot u \text {. }
$$



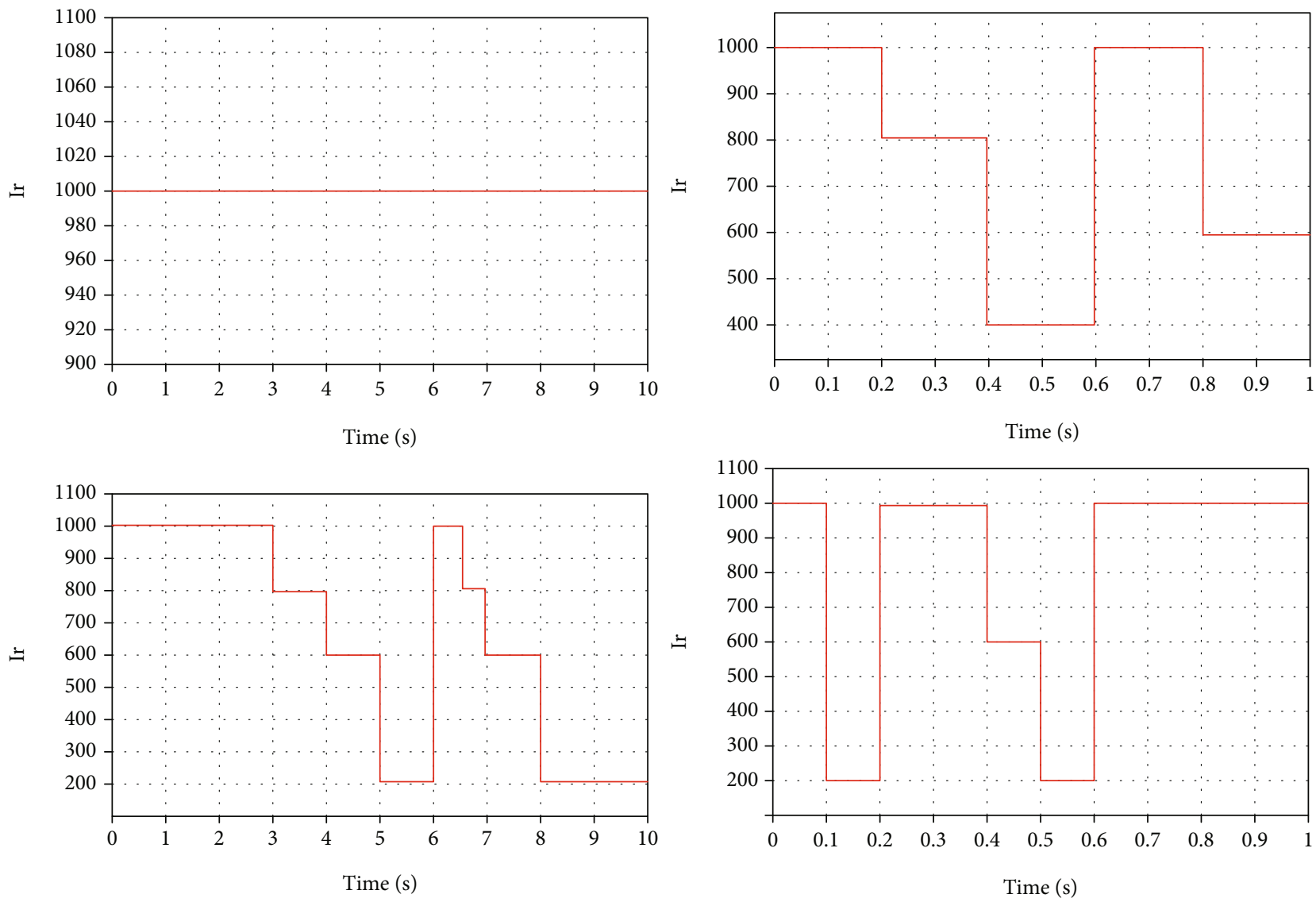

Figure 6: Different profile of irradiance and at fixed temperature at $25^{\circ} \mathrm{C}$ pattern for the test.

With

$$
x(t)=\left(x, \dot{x}, \cdots, x^{(n-1)}\right)^{T} \text { the state vector. }
$$

$f(x, t)$ and $g(x, t)$ nonlinear functions of the state vector describing the system. The purpose of tracking control is to find a control law such that, given a desired trajectory $x^{d}(t)$, the tracking error $x(t)-x^{d}(t)$ tends to zero despite the presence of disturbances. The tracking error is defined by

$$
e(t)=x(t)-x^{d}(t)=\left(e, \dot{e}, \cdots, e^{(n-1)}\right)^{T}
$$

The implementation of a sliding mode command goes through three stages:

(i) The choice of sliding surface

Slotine [78] proposed a general form, which consists in defining a scalar function of the sliding surfaces in the phase plane in order to ensure the convergence of a state variable $x$ towards its set value $x^{d}$ this function is given by the following equation:

$$
s(x, t)=\left(\frac{\partial}{\partial t}+\lambda\right)^{(n-1)} . e
$$

where

$\lambda$ is a scalar which represents the slope of the sliding surface, and the latter is obtained for a second-order system when

$$
s(x, t)=0
$$

Once the switching function is established, the tracking problem requires the design of a control law such that the state vector $e(t)$ remains on the sliding surface $s(x, t)=0$ for all $t \geq 0$.

(ii) The condition of existence of a sliding surface

It can be deduced from the energetic function of Liapunov given by the following relation:

$$
V=\frac{1}{2} S^{2}
$$



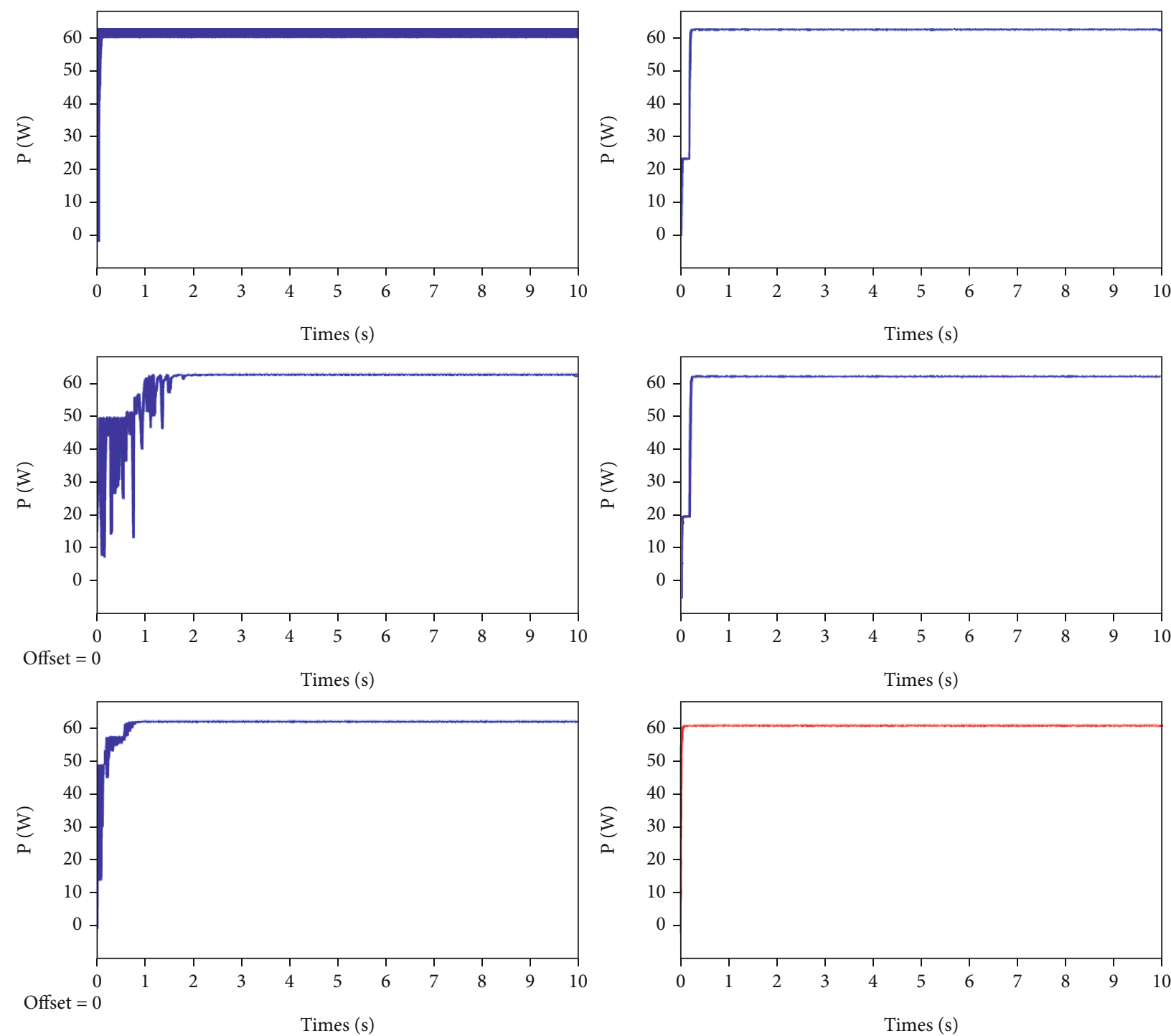

FIGURE 7: Simulation waveforms at STCs; PV array output power P\&O, PSO, CUCKOO, GWO, WOA, and SMC-PSO.

A sufficient condition for equation (8) to be stable is

$$
\dot{V}=\frac{1}{2} \frac{\partial}{\partial t}\left(S^{2}\right) \leq-\eta \cdot|S|
$$

where $\eta>0$

(iii) The establishment of the control law

The law of control by sliding mode is given by the following formula:

$$
u=u_{e}+k \cdot \operatorname{sign}(s)=u_{e}+\Delta u
$$

Knowing that

$u_{e}$ is the equivalent command.

$k$ is a positive constant, which represents the gain of the discontinuous command.
One method, which makes it possible to reduce the effect of browsing, is to replace the discontinuous function with a saturation function, which consists in determining a limit band around the sliding surface thus ensuring the smoothing of the control and the maintenance of the state of the system in this band. The control law then becomes

$$
u=u_{e}+k \cdot \operatorname{sat}(s)
$$

3.1. Design of the MPPT Hybrid Sliding Mode-PSO Controller. The objective of the MPPT hybrid sliding mode controller is to ensure that the system continuously delivers maximum power to the load by varying the duty cycle of the boost converter. In this case, the condition of maximum power is obtained when [13]

$$
\frac{d P_{\mathrm{pv}}}{d V_{\mathrm{pv}}}=0 .
$$



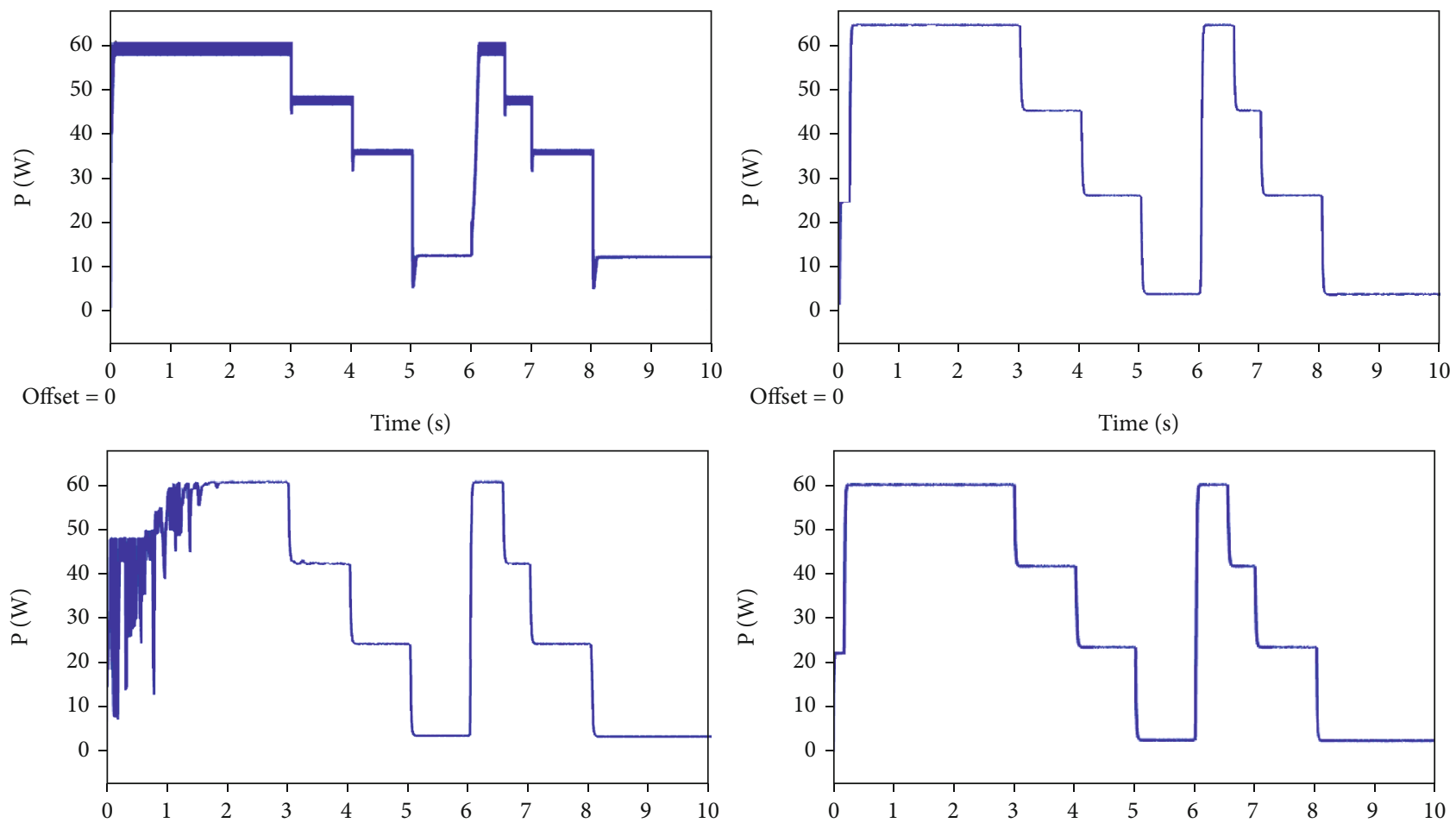

Offset $=0$
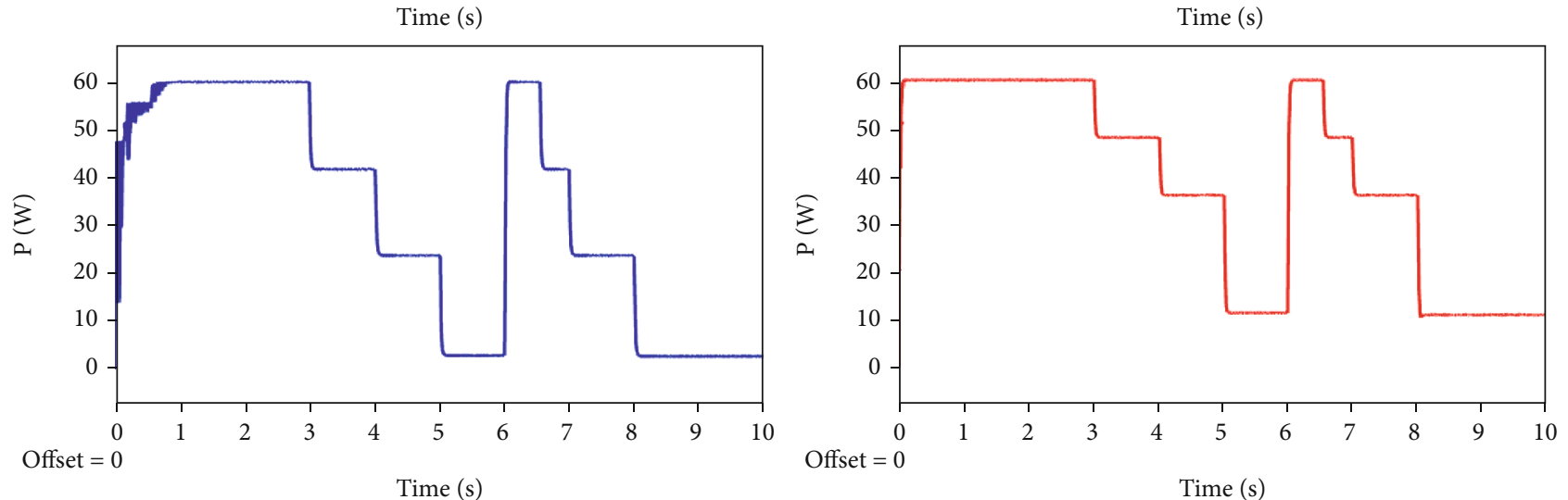

FIGURE 8: Simulation waveforms at the rapid change in insolation. PV array output power P\&O, PSO, CUCKOO, GWO, WOA, and SMCPSO.

The sliding surface is chosen as follows [13]:

$$
S(x)=\frac{d P_{\mathrm{pv}}}{d V_{\mathrm{pv}}}=I_{p v}+\frac{d I_{\mathrm{pv}}}{d V_{\mathrm{pv}}} V_{\mathrm{pv}} .
$$

Imposing the invariance conditions $[20,22,29]$ :

$$
S(x)=0 \text { and } \frac{d s(x)}{d t}=0 .
$$

In sliding mode and in steady state, the derivative of the surface is zero (because its primitive is zero), which makes it possible to determine the equivalent command as follows [13]:

$$
u_{e}=1-\frac{V_{\mathrm{pv}}}{V_{0}} .
$$

The PSO controller will replace the discontinuous part of the command represented by equation (13). Its expression is given by

$$
u=u_{e}+u_{\mathrm{pso}}
$$



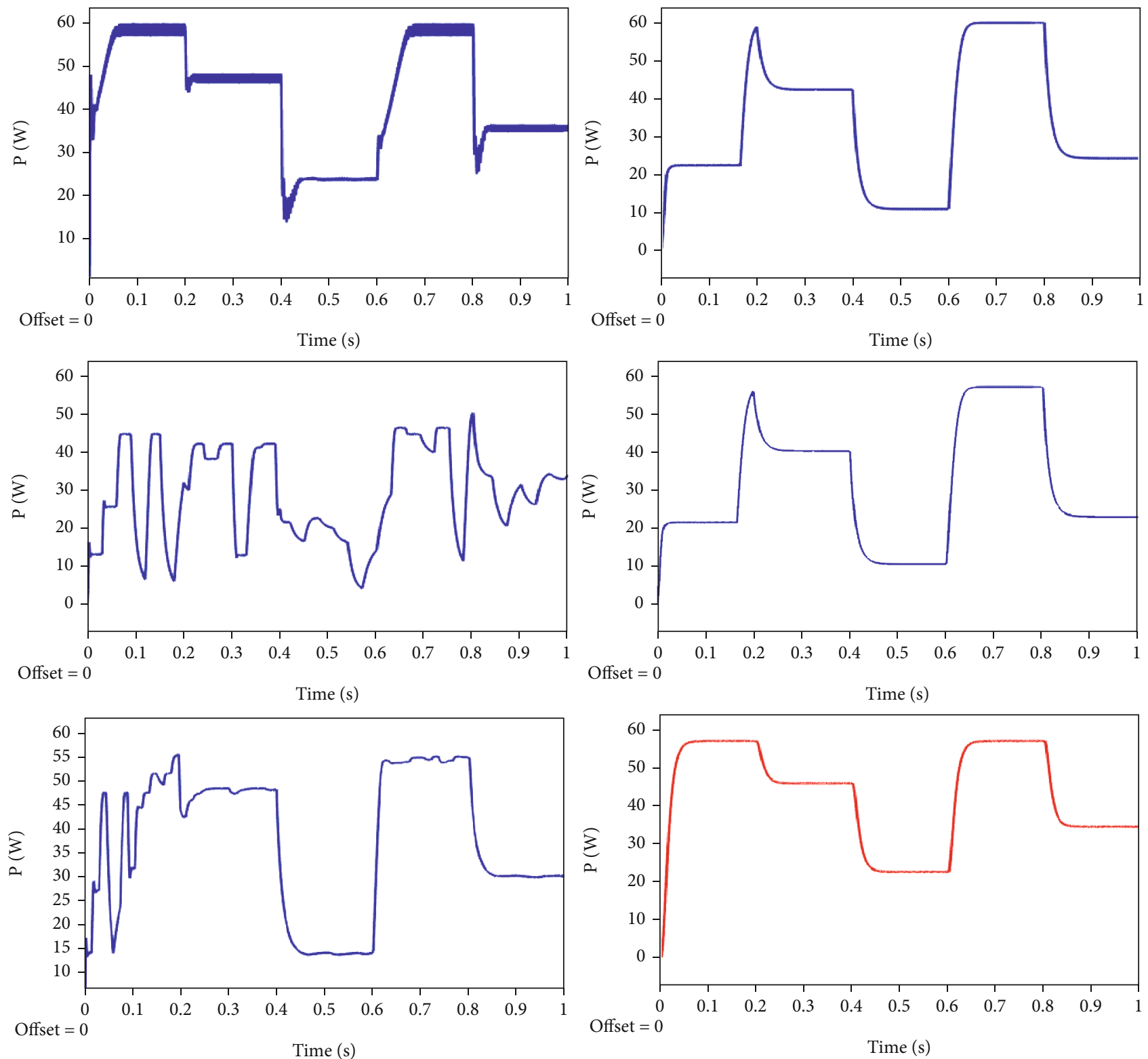

Figure 9: Simulation waveforms at the rapid change in insolation at before $1 \mathrm{s.} \mathrm{PV} \mathrm{array} \mathrm{output} \mathrm{power} \mathrm{P \& O,} \mathrm{PSO,} \mathrm{CUCKOO,} \mathrm{GWO,} \mathrm{WOA,}$ and SMC-PSO.

Of which the analytical form of the PSO command is only the following equation:

$$
u_{\text {pso }}=-k_{\text {pso }} \cdot \operatorname{sat}(s) .
$$

The global control by drag mode becomes

$$
u=u_{e}-k_{\mathrm{pso}} \cdot \operatorname{sat}(s) .
$$

The control system is presented in Figure 4.

3.2. Particle Swarm Optimization Algorithm. The PSO algorithm first developed by Kennedy and Eberhart [79] is an iterative algorithm which is part of the stochastic methods of evolutionary type with fast convergence. Many

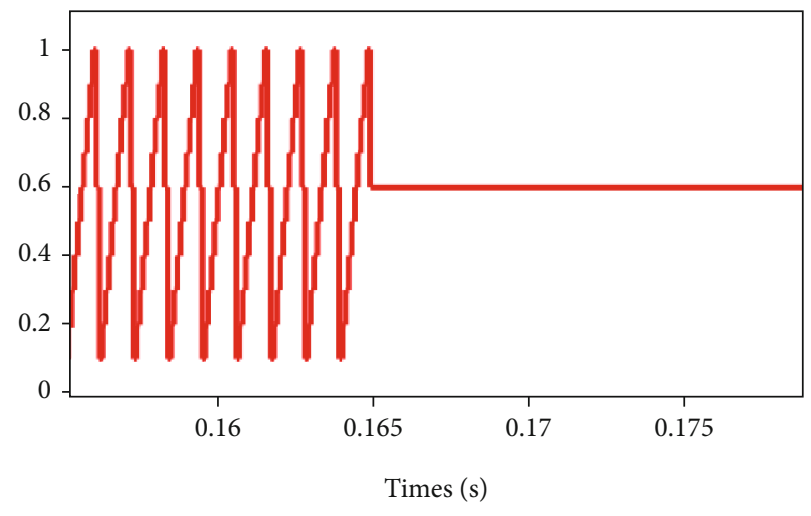

Figure 10: Duty cycle of SMC-PSO. 

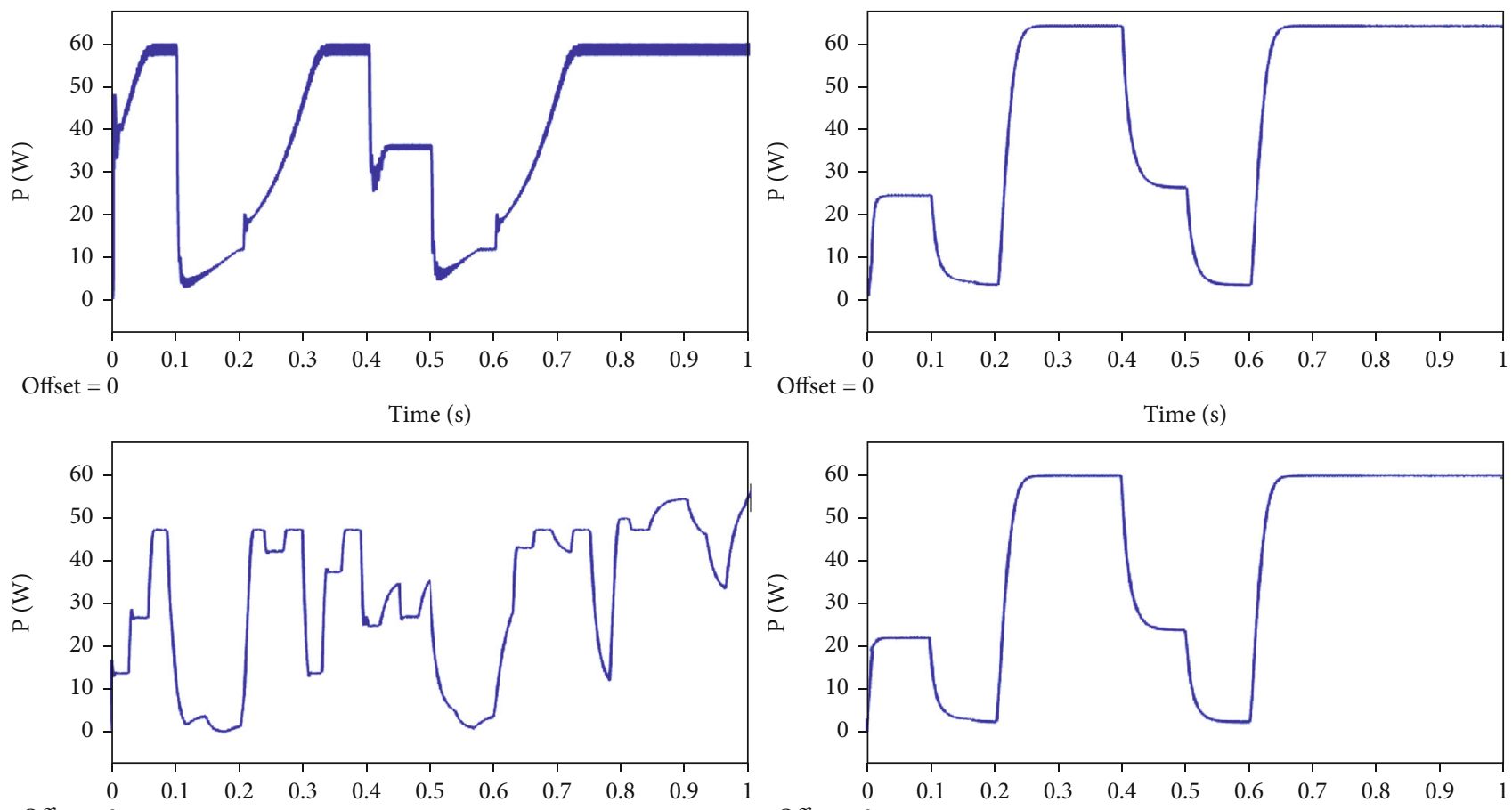

Offset $=0$

Time (s)
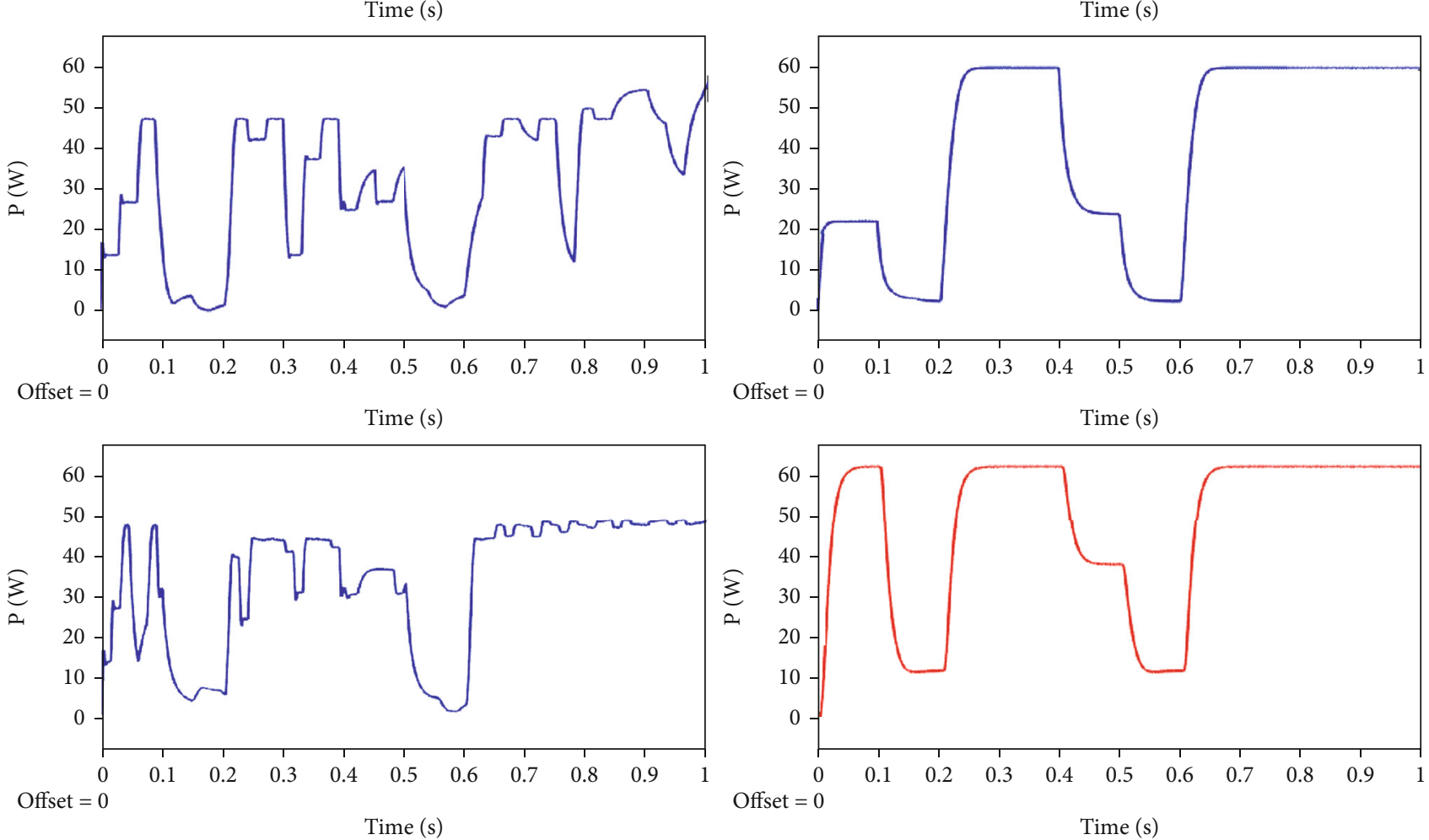

FIGURE 11: Simulation waveforms at the extreme very fast change in insolation. PV array output power P\&O, PSO, CUCKOO, GWO, WOA, and SMC-PSO.

applications of this algorithm in several fields and in particular in the field of engineering show its superiority compared to other stochastic methods such as the ant colony, biogeography, and the genetic algorithm. At each stage of calculation, the values of the individuals are compared according to the objective function; then, the new guides are chosen. During its execution, the algorithm goes through the steps grouped in the flowchart of Figure 5. The position and the speed of each particle are updated by applying the following equations:

$$
\left\{\begin{array}{l}
V_{i+1}=\gamma_{1} V_{i}+\gamma_{2}\left(x_{\mathrm{ip}}-x_{i}\right)+\gamma_{P}\left(x_{g}-x_{i}\right) \\
x_{i+1}=x_{i}+V_{i+1}
\end{array} .\right.
$$

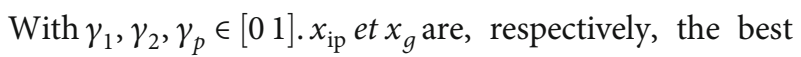
position of an ith particle from the first iteration and the best global position of the swarm.

\section{Results and Discussion}

The tests represent different simulations of the variation of the hard, medium, and soft insolation.

Four cases were considered for the test represented by Figure 6:

Parameters for the PSO algorithm are as follows: $c 1=c 2=2.05$.

Nbre_ierations $=150$.

Nbre_particule $=100$.

Vit_max $=5$.

Vit $\min =2.5$.

Under standard test conditions (STC) at Figure 7, we confirm that most techniques are stable and accurate under stable conditions. The $\mathrm{P} \& \mathrm{O}$ converges towards the PPM in $60 \mathrm{~ms}$ and reaches $57.35 \mathrm{~W}$, while the PSO takes a little longer, i.e., $2040 \mathrm{~ms}$ before converging and reaches $60.48 \mathrm{~W}$ with an oscillation of $0.015 \mathrm{~mW}$ which is negligible compared to 
TABLE 2: Comparison of MPPT algorithms for the scenario considered.

\begin{tabular}{|c|c|c|c|c|c|c|}
\hline Algorithm & $\mathrm{P} \& \mathrm{O}$ & PSO & CUCKOO & GWO & WOA & SMC-PSO \\
\hline Tracking speed at STCs & $0.4 \mathrm{~s}$ & $2 \mathrm{~s}$ & $0.75 \mathrm{~s}$ & $0.2 \mathrm{~s}$ & $0.2 \mathrm{~s}$ & $0.05 \mathrm{~s}$ \\
\hline Tracking speed after extreme change in irradiance & $0.12 \mathrm{~s}$ & $0.1 \mathrm{~s}$ & $0.75 \mathrm{~s}$ & $0.2 \mathrm{~s}$ & $0.2 \mathrm{~s}$ & $0.03 \mathrm{~s}$ \\
\hline Ability to track large changes in power before $1 \mathrm{~s}$ & Less & No & No & High & High & High \\
\hline Extracted energy efficiency (\%) & 96.3 & 99.9 & 99.93 & 99.66 & 99.70 & 96.4 \\
\hline Steady state oscillation (\% of power) & High & Less & Less & Less & Less & Less \\
\hline Accuracy & Low & Highest & Highest & Highest & Highest & Highest \\
\hline Complexity & Easy & Medium & Medium & Medium & Medium & Medium \\
\hline Transient power fluctuation before $1 \mathrm{~s}$ & Low & High & High & Medium & Medium & Very low \\
\hline Dynamic response before $1 \mathrm{~s}$ & Poor & Poor & Poor & Good & Good & Good \\
\hline
\end{tabular}

the $\mathrm{P} \& \mathrm{O}$ which oscillates a lot. Our method (SMC-PSO) compared to PSO, CUCKOO, GWO, and WOA converges rapidly $0.05 \mathrm{~s}$ without oscillation or ripple therefore faster than P\&O, PSO, CUCKOO, GWO, and WOA.

At the rapid change in irradiance, overshoots are observed in Figure 8 concerning the P\&O. These overshoots reflect the energy losses when the irradiance changes rapidly to decrease, while the PSO shows no overshoot after $2 \mathrm{~s}$ which corresponds to the convergence time but suffers from the attainment rate of the corresponding PPM when the irradiance changes rapidly while decreasing. For example, between 5 and 6 seconds, the curve of the PSO, CUCKOO, GWO, and WOA is located at $4 \mathrm{~W}$, while for the same time interval, the $\mathrm{P} \& \mathrm{O}$ and the SMC-PSO have a power locate at $12 \mathrm{~W}$. The proposed SMC-PSO therefore corrects the P\&O in terms of speed of convergence, overshoot, and oscillation and the $\mathrm{PSO}, \mathrm{CUCKOO}, \mathrm{GWO}$, and WOA in terms of initial convergence speed and rate of reaching the PPM when the irradiance changes rapidly and decreasing. The MPPT PSO, CUCKOO, GWO, and WOA algorithms are adept at following the MPP during very fast and wide variations in insolation. However, this is only possible after the convergence period, which is 2 seconds for PSO, $0.75 \mathrm{~S}$ for CUCKOO, and $0.2 \mathrm{~S}$ for GWO and WOA. The PSO follows the variations with a convergence time of $100 \mathrm{~ms}$.

Figure 9 shows that when the irradiance changes within a second, PSO and CUCKOO can no longer follow the PPM this is due to the fact that PSO requires $2 \mathrm{~s}$ and CUCKOO $0,78 \mathrm{~s}$ to converge correctly. GWO and WOA require $0.2 \mathrm{~s}$ to converge. This problem is corrected by the SMC-PSO with a convergence speed of $0,03 \mathrm{~s}$. The dynamic response of the SMC-PSO under the same conditions is good. Overshoots are observed when insolation decrease for the $\mathrm{P} \& \mathrm{O}$.

When the irradiance varies within a second and very widely (200 to $1000 \mathrm{~W} / \mathrm{m}^{2}$ ), the PSO and CUCKOO can no longer follow the PPM. The dynamic response of the SMCPSO under the same conditions remained unchanged, i.e., $0.03 \mathrm{~s}$.

Figure 10 shows the duty cycle of SMC-PSO.

The simulation results show the efficiency of the proposed algorithm in the transient response compared to P\&O, PSO, CUCKOO, GWO, and WOA. In addition, good performance in steady state (no ripple or oscillation around the MPP) was compared to the classic $\mathrm{P} \& \mathrm{O}$ algorithm. The SMC-PSO greatly reduces the chatter phenomenon.

The proposed algorithm was also subjected to a robustness test as shown in Figure 11. For this, we tested its ability to follow the MPP point in the event of a very rapid change in atmospheric conditions by performing the test as follows: the extreme, very rapid, and significant change in sunstroke. The results show that the dynamic response of our algorithm is indeed improved.

Compared to the conventional $\mathrm{P} \& \mathrm{O}$ algorithm, the proposed SMC-PSO reduces oscillations around maximum power with precise tracking (without overshoot) of the MPP point. This last point has a direct impact on the energy loss, which is less important with the proposed SMC-PSO controller. From these test results, we can conclude that the main contributions of this work are improved response time, reduced ripple and overshoot, reduced chatter, and the ability of the SMC PSO algorithm to operate efficiently in rapidly changing environmental conditions, resulting in an overall reduction in energy loss. Table 2 gives the comparison of the MPPT algorithms for the scenario considered. Table 2 gives the comparison of MPPT algorithms for the scenario considered.

\section{Conclusion}

In this paper, the optimization of sliding mode controller by PSO for PV systems under rapidly changing atmospheric conditions was presented. The bio-inspired PSO algorithm is used to find the optimal controller gain in sliding mode. The tests were performed under a very fast and large extreme change in insolation and compared to the output results of the P\&O, PSO, CUCKOO, GWO, and WOA algorithms. The simulation results demonstrate that the proposed SMC-PSO algorithm outperforms the conventional P\&O MPPT in terms of accuracy, speed, ripple and overshoot, the PSO, CUCKOO, GWO, and WOA in terms of dynamic response before $1 \mathrm{~s}$. The proposed algorithm effectively improves the dynamic response thus confirming its superiority over the MPPT P\&O, PSO, CUCKOO, GWO, and WOA algorithms for all of the performance measures evaluated. The robustness of the proposed algorithm was also presented. The main limit remains the energy efficiency 
extracted which is lower than the PSO, CUCKOO, GWO, and WOA. In the next article, we plan to carry out the proposed control scheme experimentally.

\section{Nomenclature}

\begin{tabular}{|c|c|}
\hline A: & Ideality factor of the PN junction \\
\hline$K=1.3805 \times 10^{-23} \mathrm{~J} / \mathrm{K}:$ & Boltzmann's constant \\
\hline $\mathrm{q}=1.6 \times 10^{-19}[\mathrm{C}]:$ & Charge of the electrons \\
\hline $\mathrm{T}[\mathrm{K}]:$ & Temperature of the cell \\
\hline $\mathrm{Eg}=1.12[\mathrm{eV}]:$ & $\begin{array}{l}\text { Band gap energy of the semicon- } \\
\text { ductor used in the PV cell }\end{array}$ \\
\hline$I_{O}:$ & Inverse saturation current \\
\hline Iph $[A]:$ & Photo-current \\
\hline Ior: & Inverse saturation current at $\mathrm{Tr}$ \\
\hline$I_{\mathrm{PV}}[\mathrm{A}]:$ & Current of the PV module \\
\hline Iscr $[\mathrm{A}]:$ & $\begin{array}{l}\text { Cell's short-circuit current at the } \\
\text { reference irradiation and } \\
\text { temperature }\end{array}$ \\
\hline Np: & $\begin{array}{l}\text { Number of cells connected in } \\
\text { parallel }\end{array}$ \\
\hline Ns: & Number of cells connected in series \\
\hline $\operatorname{Tr}[\mathrm{K}]:$ & Reference temperature of the cell \\
\hline Voc $[\mathrm{V}]:$ & Open-circuit voltage \\
\hline
\end{tabular}

\section{Data Availability}

No data were used to support this study.

\section{Conflicts of Interest}

The authors declare no conflicts of interest.

\section{References}

[1] A. Parisi, L. Curcio, V. Rocca et al., "Photovoltaic module characteristics from CIGS solar cell modelling," in International Conference on Renewable Energy Research and Applications (ICRERA), pp. 1139-1144, Madrid, Spain, 2013.

[2] N. K. Shukla, S. Rangnekar, and K. Sudhakar, "Mathematical modelling of solar radiation incident on tilted surface for photovoltaic application at Bhopal, M.P.,India," International Journal of Ambient Energy, vol. 37, no. 6, pp. 579-588, 2016.

[3] N. Karami, N. Moubayed, and R. Outbib, "General review and classification of different MPPT techniques," Renewable and Sustainable Energy Reviews, vol. 68, pp. 1-18, 2017.

[4] A. K. Abdelsalam, A. M. Massoud, S. Ahmed, and P. N. Enjeti, "High-performance adaptive perturb and observe MPPT technique for photovoltaic-based microgrids," IEEE Transactions on Power Electronics, vol. 26, no. 4, pp. 1010-1021, 2011.

[5] J. Ahmed and Z. Salam, "An improved perturb and observe (P\&O) maximum power point tracking (MPPT) algorithm for higher efficiency," Applied Energy, vol. 150, pp. 97-108, 2015.

[6] L. Fangrui, S. Duan, F. Liu, B. Liu, and Y. Kang, "A variable step size INC MPPT method for PV systems," IEEE Transactions on Industrial Electronics, vol. 55, no. 7, pp. 2622-2628, 2008.

[7] P. Sivakumar, A. Abdul Kader, Y. Kaliavaradhan, and M. Arutchelvi, "Analysis and enhancement of PV efficiency with incremental conductance MPPT technique under nonlinear loading conditions," Renewable Energy, vol. 81, pp. 543-550, 2015.

[8] K. S. Tey and S. Mekhilef, "Modified incremental conductance MPPT algorithm to mitigate inaccurate responses under fastchanging solar irradiation level," Solar Energy, vol. 101, pp. 333-342, 2014.

[9] T. Noguchi, S. Togashi, and R. Nakamoto, "Short-current pulse-based maximum-power-point tracking method for multiple photovoltaic-and-converter module system," IEEE Transactions on Industrial Electronics, vol. 49, no. 1, pp. $217-$ 223, 2002.

[10] K. Kobayashi, H. Matsuo, and Y. Sekine, "A novel optimum operating point tracker of the solar cell power supply system," in In 2004 IEEE 35th Annual Power Electronics Specialists Conference (IEEE Cat. No.04CH37551), pp. 2147-2151, Aachen, Germany, 2004.

[11] A. Mehiri, M. Bettayeb, A. K. Hamid, and A. Ardjal, "Fractional nonlinear synergetic control for DC-link voltage regulator of three phase inverter grid-tied PV system," in 5th International Conference on Renewable Energy: Generation and Applications (ICREGA), pp. 90-93, Al Ain, United Arab Emirates, 2018.

[12] S. Sajadian, R. Ahmadi, and H. Zargarzadeh, "Extremum seeking-based model predictive MPPT for grid-tied Z-source inverter for photovoltaic systems," IEEE Journal of Emerging and Selected Topics in Power Electronics, vol. 7, no. 1, pp. 216-227, 2019.

[13] M. Kermadi and E. M. Berkouk, "Artificial intelligence-based maximum power point tracking controllers for Photovoltaic systems: comparative study," Renewable and Sustainable Energy Reviews, vol. 69, pp. 369-386, 2017.

[14] M. Premkumar and R. Sowmya, An effective maximum power point tracker for partially shaded solar photovoltaic systems, Elsevier Ltd, 2019.

[15] K. S. Tey and S. Mekhilef, "A fast-converging MPPT technique for photovoltaic system under fast-varying solar irradiation and load resistance," IEEE Transactions on Industrial Informatics, vol. 11, no. 1, 2014.

[16] S. Mohanty, B. Subudhi, and P. K. Ray, “A new MPPT design using grey wolf optimization technique for photovoltaic system under partial shading conditions," Ieee Transactions On Sustainable Energy, vol. 7, no. 1, pp. 181-188, 2016.

[17] C. Huang, L. Wang, R. S.-C. Yeung, Z. Zhang, H. S.-H. Chung, and A. Bensoussan, "A prediction model-guided Jaya algorithm for the PV system maximum power point tracking," IEEE Transactions on Sustainable Energy, vol. 9, no. 1, pp. 45-55, 2018.

[18] S. Padmanaban, N. Priyadarshi, M. S. Bhaskar, J. B. HolmNielsen, E. Hossain, and F. Azam, "A hybrid photovoltaicfuel cell for grid integration with Jaya-based maximum power point tracking: experimental performance evaluation," IEEE Access, vol. 7, pp. 82978-82990, 2019.

[19] S. Padmanaban, N. Priyadarshi, J. B. Holm-Nielsen et al., "A novel modified sine-cosine optimized MPPT algorithm for grid integrated PV system under real operating conditions," IEEE Access, vol. 7, pp. 10467-10477, 2019.

[20] A. Badis, M. N. Mansouri, and M. H. Boujmil, "A genetic algorithm optimized MPPT controller for a PV system with DCDC boost converter," in 2017 International Conference on Engineering \& MIS (ICEMIS),, pp. 1-6, Monastir, 2017. 
[21] S. Daraban, D. Petreus, and C. Morel, "A novel MPPT (maximum power point tracking) algorithm based on a modified genetic algorithm specialized on tracking the global maximum power point in photovoltaic systems affected by partial shading," Energy, vol. 74, pp. 374-388, 2014.

[22] A. S. Benyoucef, A. Chouder, K. Kara, S. Silvestre, and O. A. Sahed, "Artificial bee colony based algorithm for maximum power point tracking (MPPT) for PV systems operating under partial shaded conditions," Applied Soft Computing, vol. 32, pp. 38-48, 2015.

[23] I. Shams, S. Mekhilef, and K. S. Tey, "Maximum Power Point Tracking Using Modified Butterfly Optimization Algorithm for Partial Shading, Uniform Shading, and Fast Varying Load Conditions," IEEE Transactions on Power Electronics, vol. 36, 2021.

[24] N. Priyadarshi, V. Ramachandaramurthy, S. Padmanaban, and F. Azam, "An ant colony optimized MPPT for standalone hybrid PV-wind power system with single cuk converter," Energies, vol. 12, no. 1, p. 167, 2019.

[25] H. Boumaaraf, A. Talha, and O. Bouhali, "A three-phase NPC grid-connected inverter for photovoltaic applications using neural network MPPT," Renewable and Sustainable Energy Reviews, vol. 49, pp. 1171-1179, 2015.

[26] A. K. Rai, N. D. Kaushika, B. Singh, and N. Agarwal, "Simulation model of ANN based maximum power point tracking controller for solar PV system," Solar Energy Materials and Solar Cells, vol. 95, no. 2, pp. 773-778, 2011.

[27] N. H. Saad, A. A. El-Sattar, and A. E.-A. M. Mansour, "Improved particle swarm optimization for photovoltaic system connected to the grid with low voltage ride through capability,” Renewable Energy, vol. 85, pp. 181-194, 2016.

[28] K. Ishaque and Z. Salam, "A deterministic particle swarm optimization maximum power point tracker for photovoltaic system under partial shading condition," IEEE Transactions on Industrial Electronics, vol. 60, 2012.

[29] E. K. Ahmad, N. A. Rahim, J. Selvaraj, and M. N. Uddin, "Fuzzy logic controller based SEPIC converter for maximum power point tracking," IEEE Transactions on Industry Applications, vol. 50, no. 4, pp. 2349-2358, 2014.

[30] R. Arulmurugan and N. Suthanthiravanitha, "Model and design of a fuzzy-based Hopfield NN tracking controller for standalone PV applications," Electric Power Systems Research, vol. 120, pp. 184-193, 2015.

[31] M. Farhat, O. Barambones, and L. Sbita, "Efficiency optimization of a DSP-based standalone PV system using a stable single input fuzzy logic controller," Renewable and Sustainable Energy Reviews, vol. 49, pp. 907-920, 2015.

[32] H. Rezk, M. Aly, M. Al-Dhaifallah, and M. Shoyama, "Design and hardware implementation of new adaptive fuzzy logicbased MPPT control method for photovoltaic applications," IEEE Access, vol. 7, pp. 106427-106438, 2019.

[33] J. Ahmed and Z. Salamn, “A critical evaluation on maximum power point tracking methods for partial shading in PV systems," Renewable and Sustainable Energy Reviews, vol. 47, pp. 933-953, 2015.

[34] L. Shengqing, L. Fujun, Z. Jian, C. Wen, and Z. Donghui, "An improved MPPT control strategy based on incremental conductance method," Soft Computing, vol. 24, pp. 6039-6046, 2020.

[35] A. H. Al Qahtani and V. I. Utkin, "Control of photovoltaic system power generation using sliding mode control," in 2012 IEEE International Conference on Power System Technology (POWERCON), pp. 1-6, Auckland, New Zealand, 2012.
[36] Y. Levron and D. Shmilovitz, "Maximum power point tracking employing sliding mode control," IEEE Transactions on Circuits and Systems I: Regular Papers, vol. 60, no. 3, pp. 724732, 2013.

[37] F. Mohd Zaihidee, S. Mekhilef, and M. Mubin, "Robust speed control of PMSM using sliding mode control (SMC) - a review," Energies, vol. 12, no. 9, p. 1669, 2019.

[38] A. Merabet, L. Labib, A. M. Y. M. Ghias, C. Ghenai, and T. Salameh, "Robust feedback linearizing control with sliding mode compensation for a grid-connected photovoltaic inverter system under unbalanced grid voltages," Journal of Photovoltaics, vol. 7, no. 3, pp. 828-838, 2017.

[39] A. T. Azar, F. E. Serrano, S. Vaidyanathan, and H. Albalawi, In adaptive higher order sliding mode control for robotic manipulators with matched and mismatched uncertainties, Springer International Publishing, 2020.

[40] A. Ardjal, R. Mansouri, and M. Bettayeb, "Fractional sliding mode control of wind turbine for maximum power point tracking," Transactions of the Institute of Measurement and Control, vol. 41, no. 2, pp. 447-457, 2019.

[41] V. I. Utkin, "Survey paper: variable structure systems with sliding modes," IEEE Transactions on Automatic Control, vol. 22, no. 2, pp. 212-222, 1977.

[42] C.-C. Chu and C.-L. Chen, "Robust maximum power point tracking method for photovoltaic cells: a sliding mode control approach," Solar Energy, vol. 83, no. 8, pp. 1370-1378, 2009.

[43] M. R. Mojallizadeh, M. Badamchizadeh, S. Khanmohammadi, and M. Sabahi, "Designing a new robust sliding mode controller for maximum power point tracking of photovoltaic cells," Solar Energy, vol. 132, pp. 538-546, 2016.

[44] H.-T. Yau and C.-L. Chen, "Fuzzy sliding mode controller design for maximum power point tracking control of a solar energy system," Transactions of the Institute of Measurement and Control, vol. 34, no. 5, pp. 557-565, 2012.

[45] F. Zhang, J. Maddy, G. Premier, and A. Guwy, "Novel current sensing photovoltaic maximum power point tracking based on sliding mode control strategy," Solar Energy, vol. 118, pp. 80-86, 2015.

[46] M. A. Enany, M. A. Farahat, and A. Nasr, "Modeling and evaluation of main maximum power point tracking algorithms for photovoltaics systems," Renewable and Sustainable Energy Review, vol. 58, pp. 1578-1586, 2016.

[47] G. J. Kish, J. J. Lee, and P. W. Lehn, "Modelling and control of photovoltaic panels utilising the incremental conductance method for maximum power point tracking," IET Renewable Power Generation, vol. 6, no. 4, p. 259, 2012.

[48] M. Farhat, O. Barambones, J. A. Ramos, and J. M. Durana, "Maximum power point tracking controller based on sliding mode approach," Actas de Las XXXV Jornadas de Automática, pp. 3-5, 2014.

[49] G. Javid, D. O. Abdeslam, and D. Benyoucef, "Maximum power point tracking of photovoltaic power system with adaptive fuzzy terminal sliding mode controller," in IEEE International Conference on Environment and Electrical Engineering and 2018 IEEE Industrial and Commercial Power Systems Europe (EEEIC /IఓCPS Europe), vol. 6, pp. 1-6, Palermo, Italy, 2018.

[50] R. Garraoui, A. E. Aroudi, and M. B. Hamed, "A comparative study between two MPPT controllers based on the principe of sliding-mode control theory and intelligent control technique in photovoltaic systems," Proceedings of the Mediterranean Conference on Information \& Communication Technologies, vol. 380, pp. 505-515, 2016. 
[51] H. Yatimi and E. Aroudam, "Assessment and control of a photovoltaic energy storage system based on the robust sliding mode MPPT controller," Solar Energy, vol. 139, pp. 557-568, 2016.

[52] R. Pradhan and B. Subudhi, "Double Integral Sliding Mode MPPT Control of a Photovoltaic System," IEEE Transactions On Control Systems Technology, vol. 24, no. 1, pp. 285-292, 2015.

[53] D. G. Montoya, C. A. Ramos-Paja, and R. Giral, "Improved design of sliding mode controllers based on the requirements of MPPT techniques," IEEE Transactions on Power Electronics, vol. 31, no. 1, pp. 235-247, 2015.

[54] A. Ortiz-Valencia, L. A. Trejos-Grisales, and C. A. RamosPaja, "Maximum power point tracking in PV systems based on adaptive control and sliding mode control," Revista Facultad de Ingeniería Universidad de Antioquia, no. 75, pp. 6779, 2015.

[55] V. R. Kolluru, G. Sahu, K. Mahapatra, and B. Subudhi, "Design and simulation of a modified sliding mode controller evaluated with a conventional P\&O MPPT controller for solar applications," in 2015 IEEE International Conference on Signal Processing, Informatics, Communication and Energy Systems, vol. 7, Kozhikode, India, 2015.

[56] K. Boulâam and A. Boukhelifa, "Maximum power point tracking based on sliding mode control," International Journal of Photogramm, vol. 1, p. 8, 2015.

[57] A. Harrag and S. Messalti, "PSO-based SMC variable step size $\mathrm{P} \& \mathrm{O}$ MPPT controller for PV systems under fast changing atmospheric conditions," International Journal of Numerical Modelling, vol. 32, no. 5, p. e2603, 2019.

[58] V. Utkin, J. Guldner, and J. Shi, Sliding Mode Control in Electro-Machanical Systems, CRC Press, 2nd edition, 2009.

[59] J. Fei and C. Lu, "Adaptive fractional order sliding mode controller with neural estimator," Journal of the Franklin Institute, vol. 355, no. 5, pp. 2369-2391, 2018.

[60] L. Wu, Y. Gao, J. Liu, and H. Li, "Event-triggered sliding mode control of stochastic systems via output feedback," Automatica, vol. 82, pp. 79-92, 2017.

[61] Y. Chu, J. Fei, and S. Hou, "Dynamic global proportional integral derivative sliding mode control using radial basis function neural compensator for three-phase active power filter," Transactions of the Institute of Measurement and Control, vol. 40, no. 12, pp. 3549-3559, 2017.

[62] J. Lu and C. Fei, "Adaptive Sliding Mode Control of Dynamic Systems Using Double Loop Recurrent Neural Network Structure," IEEE Transactions on Neural Networks and Learning Systems, vol. 9, no. 4, pp. 1275-1286, 2017.

[63] J. Fei and T. Wang, "Adaptive Fuzzy-Neural-Network Based on RBFNN Control for Active Power Filter," International Journal of Machine Learning and Cybernetics, vol. 10, no. 5, pp. 1139-1150, 2018.

[64] B. K. Park and T. Tsuiji, "Terminal sliding mode control of second-order nonlinear uncertain systems," International Journal of Robust and Nonlinear Control, vol. 9, no. 11, pp. 769-780, 1999.

[65] C. S. Chiu, Y. L. Ouyang, and C. Y. Ku, “Terminal sliding mode control for maximum power point tracking of photovoltaic power generation systems," Solar Energy, vol. 86, no. 10, pp. 2986-2995, 2012.

[66] Z. Asma, D. Karim, and D. Tarak, "Maximum power point tracking of photovoltaic systems based on fast terminal sliding mode controller," International Journal of Renewable Energy Research (IJRER), vol. 6, no. 14, pp. 1435-1445, 2016.

[67] S. S. T. Amirineni, M. J. Morshed, and A. Fekih, "Integral terminal sliding mode control for maximum power production in grid connected PV systems," IEEE Conference on Control Applications (CCA), pp. 1560-1565, 2016.

[68] M. R. Mojallizadeh and M. A. Badamchizadeh, "Second-order fuzzy sliding-mode control of photovoltaic power generation systems," Solar Energy, vol. 149, pp. 332-340, 2017.

[69] G. Garcia, A. Sellami, and W. Saad, "Terminal sliding mode control-based MPPT for a photovoltaic system with uncertainties," International Journal of Modelling, Identification and Control, vol. 29, no. 2, p. 118, 2018.

[70] A. Shahdadi, S. M. Barakati, and A. Khajeh, "Design and implementation of an improved sliding mode controller for maximum power point tracking in a SEPIC based on PV system," Engineering Reports, vol. 1, no. 4, pp. 1-20, 2019.

[71] K. Kamalapathi, N. Priyadarshi, S. Padmanaban et al., "A hybrid moth-flame fuzzy logic controller based integrated cuk converter fed brushless DC motor for power factor correction," Electronics, vol. 7, p. 288, 2018.

[72] M. Vardia, N. Priyadarshi, I. Ali, F. Azam, and A. K. Bhoi, "Maximum power point tracking for wind energy conversion system," in Advances in Greener Energy Technologies. Green Energy and TechnologySpringer, Singapore.

[73] M. Vardia, N. Priyadarshi, I. Ali, F. Azam, and A. K. BhoiG. S. Chae, "Design of wind energy conversion system under different fault conditions," in Advances in Greener Energy Technologies. Green Energy and TechnologySpringer, Singapore.

[74] T. Choudhary, N. Priyadarshi, P. Kumar, F. Azam, and A. K. Bhoi, "A fuzzy logic control based vibration control system for renewable application," in Advances in Greener Energy Technologies. Green Energy and TechnologySpringer, Singapore.

[75] A. Belkaid, J. P. Gaubert, A. Gherbi, and L. Rahmani, "Maximum power point tracking for photovoltaic systems with boost converter sliding mode control," in IEEE 23rd International Symposium on Industrial Electronics (ISIE), pp. 556561, Istanbul, Turkey, 2014.

[76] B. Mehimmedetsi and R. Chenni, "Modelling of DC PV System with MPPT," in International Renewable and Sustainable Energy Conference (IRSEC), Marrakech, Morocco, 2016.

[77] J. A. Ramos-Hernanz, J. J. Campayo, J. Larranaga et al., "Two photovoltaic cell simulation models in matlab/Simulink," International Journal on Technical and Physical Problems of Engineering (IJTPE), vol. 4, pp. 45-51, 2012.

[78] J. J. Slotine and W. Li, Applied Nonlinear Control, Englewood Cliffs, NJ:prentice Hall, 1991.

[79] J. Kennedy and R. Eberhart, "Particle swarm optimisation," Proceedings IEEE international conference neural networks, vol. 4, pp. 1942-1948, 1995. 